\title{
Correction to: High dose brachytherapy with non sealed 188Re (rhenium) resin in patients with non-melanoma skin cancers (NMSCs): single center preliminary results
}

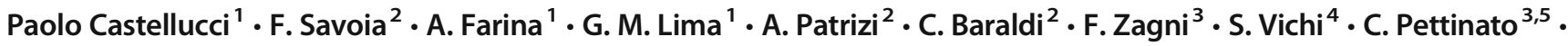 \\ A. G. Morganti ${ }^{6} \cdot$ L. Strigari ${ }^{3} \cdot$ S. Fanti $^{1}$ \\ Published online: 19 April 2021 \\ (C) Springer-Verlag GmbH Germany, part of Springer Nature 2021
}

\section{Correction to Eur J Nucl Med Mol Imaging https://doi.org/10.1007/s00259-020-05088-Z}

The article "High dose brachytherapy with non sealed 188Re (rhenium) resin in patients with non-melanoma skin cancers (NMSCs): single center preliminary results", written by Paolo Castellucci, F. Savoia, A. Farina, G. M. Lima, A. Patrizi, C. Baraldi, F. Zagni, S. Vichi, C. Pettinato, A. G. Morganti, L. Strigari, and S. Fanti, was originally published Online First without Open Access. After being published online, the authors decided to opt for Open Choice and to make the article an Open Access publication. Therefore, the copyright of the article has been changed to $($ The Author(s) 2021 and the article is forthwith distributed under the terms of the Creative Commons Attribution 4.0 International License, which permits use, sharing, adaptation, distribution and reproduction in any medium or format, as long as you give appropriate credit to the original

This article is part of the Topical Collection on Erratum.

The online version of the original article can be found at https://doi.org/10. 1007/s00259-020-05088-z

Paolo Castellucci

paolo.castellucci@aosp.bo.it

1 Nuclear Medicine, IRCCS Azienda Ospedaliero-Universitaria di Bologna, Via Massarenti 9, 40138 Bologna, Italy

2 Dermatology, IRCCS Azienda Ospedaliero-Universitaria di Bologna, Via Massarenti 9, 40138 Bologna, Italy

3 Medical Physics, IRCCS Azienda Ospedaliero-Universitaria di Bologna, Via Massarenti 9, 40138 Bologna, Italy author(s) and the source, provide a link to the Creative Commons licence, and indicate if changes were made. The images or other third party material in this article are included in the article's Creative Commons licence, unless indicated otherwise in a credit line to the material. If material is not included in the article's Creative Commons licence and your intended use is not permitted by statutory regulation or exceeds the permitted use, you will need to obtain permission directly from the copyright holder. To view a copy of this licence, visit http:// creativecommons.org/licenses/by/4.0/. Some corrections also needs to be incorporated in the "Conclusions" section and in the legends of some of the figures.

The original article has been corrected.

Publisher's note Springer Nature remains neutral with regard to jurisdictional claims in published maps and institutional affiliations. 